British Heart fournal, 1977, 39, 829-833

\title{
Improvement of myocardial metabolism in coronary arterial disease by beta-blockade
}

\author{
GRAHAM JACKSON, LYNNE ATKINSON, AND SAMUEL ORAM \\ From the Cardiac Department, King's College Hospital, London
}

Twenty patients with angina pectoris associated with obstructive coronary arterial disease were investigated by stressing the heart by atrial pacing. Arterial and coronary sinus blood was sampled and the time taken to provoke angina (pacing time) measured. Nine of the patients acted as a control group and did not receive beta-blocking drugs. In this group both pacing time and myocardial lactate extraction were reproducible provided that 45 minutes rest was allowed between pacing tests: we have called this period the myocardial recovery time. The 11 remaining patients were paced before and after beta-blockade, the rate being kept constant for each patient. In contrast to the control group, beta-blockade improved myocardial metabolism as shown by increased myocardial lactate extraction $(P<0.02)$ and decreased glucose extraction $(P<0.01)$. The pacing time to angina was increased $(P<0.01)$ and the degree of $S T$ segment depression was decreased $(P<0.05)$. There was no significant effect on systolic or diastolic blood pressure, myocardial oxygen extraction, or extraction of free fatty acids and potassium.

Failure to allow adequate time for full myocardial recovery after pacing will invalidate assessment of antianginal drugs. When this precaution is taken beta-blocking drugs are seen to improve myocardial metabolism independently of their effects on heart rate and blood pressure.

Adrenergic beta-receptor antagonists are well established in the treatment of angina pectoris (Jackson et al., 1975). Their beneficial effects are related to the reduction of left ventricular work by a reduction in heart rate, arterial pressure, and velocity of myocardial contraction (Robinson, 1971). By eliminating the effect of heart rate by means of atrial pacing, Balcon (1971) concluded that the main beneficial effect of propranolol and practolol was the reduction of heart rate.

The interpretation of an atrial pacing stress test relies to a large extent on the subjective sensation of chest pain. The addition of arterial and coronary sinus sampling, and particularly estimation of lactate, provides a more objective measurement of the response of the left ventricle to stress. This study demonstrates the reproducibility of the change in lactate extraction when the atrial pacing rate is constant and the time interval between successive pacing tests is also adequate. The beneficial effects of adrenergic beta-receptor antagonists in patients with obstructive coronary arterial disease is also confirmed.

Received for publication 29 November 1976

\section{Subjects and methods}

\section{PATIENTS}

Twenty patients, 16 men and 4 women, with exercise-induced angina pectoris, were studied after informed written consent. The average age was 50 years and ranged from 31 to 70 years.

Coronary angiography had previously shown narrowings greater than 50 per cent in 1 major vessel in 3 patients, in 2 vessels in 7 patients, and in 3 vessels in 10 patients. The left ventricular ejection fraction was greater than 50 per cent in all but 2 patients. Before the study they were maximally exercised under standard conditions to determine the peak exercise heart rate (Jackson et al., 1975). No patient received any medication on the day of the study. Digoxin was discontinued 2 weeks previously and oral beta-blocking drugs 1 week previously. The patients were studied in the non-fasting state.

\section{CORONARY SINUS PACING STUDY}

This was performed at a different time from coronary arteriography. After the patient had rested for 45 minutes, a Zucker bipolar electrode catheter 
(Zucker et al., 1965), was inserted into an antecubital vein and positioned fluoroscopically $2 \mathrm{~cm}$ within the coronary sinus as viewed in the anteroposterior projection. The position was repeatedly checked throughout the study by fluoroscopy and injection of contrast medium. Arterial samples were obtained from a two-way tap attached to manometer tubing and a 2 in No. 19G needle which had been inserted into the femoral artery under local anaesthesia. Femoral arterial pressure was recorded throughout the study on a Mingograph 81 recorder. Both the venous catheter and arterial needle were intermittently flushed with heparinised saline except when free fatty acids (FFA) were being measured, when saline alone was used. Before pacing, at least 2 control samples were taken simultaneously from the coronary sinus and from the femoral artery. Using a battery-powered pacemaker (Devices) the heart rate was increased at 5-second intervals by increments of 10 beats a minute and then held constant at least 10 beats a minute above the peak exercise rate or the maximum predicted heart rate (Andersen et al., 1971), whichever was the greater. Pacing was discontinued when the patient experienced his usual chest discomfort or pain, not breathlessness, of a severity that would stop him in his normal daily life. Blood samples were taken at peak pacing rate and at 2,5 , and 10 minutes after pacing had stopped. Electrocardiographic recordings were made throughout the study. Slight variations in methodology will be discussed with the results of each group.

\section{MEASUREMENTS}

Lactate estimations were by Livesley's modification of Hohorst's method (Livesley and Atkinson, 1974). FFA (Duncombe, 1963), oxygen saturation, potassium, and glucose, were also measured before and after pacing. The amount of ST segment depression in V5 was measured before and after pacing, disregarding the first two post-pacing beats (Parker et al., 1969). A downward-sloping ST depression of at least $1 \mathrm{~mm}$ persisting for $0.08 \mathrm{~s}$ or longer was considered indicative of ischaemia (Jackson et al., 1975). Myocardial extraction ratio is calculated as the difference between arterial and coronary sinus lactates divided by arterial lactate and is then expressed as a percentage. A myocardial lactate extraction of less than 10 per cent on peak pacing, or coronary sinus lactate greater than arterial lactate, indicates ischaemia (Herman et al., 1967). Myocardial extractions of glucose, FFA, potassium, and oxygen were calculated in the same way. Statistical analysis employed Student's paired $t$ test.

\section{Results}

No ill effects resulted from the investigations.

\section{CONTROL PATIENTS}

In order to assess the effects of beta-blockade, it was essential to determine the time to pain, and myocardial lactate extraction, during an initial pacing stress test and the interval between tests for a similar result to be obtained. Nine patients were paced at an identical rate for a second time at varying intervals after their initial pacing test. Only when the pacing test was repeated at an interval of at least 45 minutes after the original pacing test, were the pacing time, degree of depression of the ST segment, arteriovenous lactate difference, and myocardial lactate extraction reproducible, and the differences between the two pacing tests not statistically significant (Fig. 1, Table 1). We have called this period the myocardial recovery time (MRT). It is interesting to note that in 2 patients paced again less than 45 minutes after the initial pacing an improved result was associated with a well-developed collateral supply shown angiographically.

\section{PATIENTS RECEIVING BETA-BLOCKERS}

Six patients were restudied after intravenous tolamolol $(0 \cdot 15 \mathrm{mg} / \mathrm{kg})$ and 5 after intravenous propranolol $(0 \cdot 1 \mathrm{mg} / \mathrm{kg})$. Preliminary work had shown that, within 15 minutes of these drugs being given intravenously, plasma levels of the betablocker within the coronary sinus were stable. The drugs were injected 30 minutes after the original

Table 1 Control pacing study: second pacing 45 minutes after the first (5 patients)

\begin{tabular}{|c|c|c|c|c|}
\hline & & First pacing test & Second pacing test & $P$ \\
\hline $\begin{array}{l}\text { Pacing time (s) } \\
\text { ST depression (mm) } \\
\text { Arteriovenous lactate difference }(\mathrm{mg} / 100 \mathrm{ml}) \\
\text { Myocardial lactate extraction }(\%)\end{array}$ & $\begin{array}{l}\text { Resting } \\
\text { Resting minus peak pacing }\end{array}$ & $\begin{array}{l}134 \pm 19 \cdot 2 \\
1 \cdot 00 \pm 0 \cdot 35 \\
2 \cdot 32 \pm 0 \cdot 43 \\
1 \cdot 56 \pm 0 \cdot 47 \\
9 \cdot 14 \pm 5 \cdot 78\end{array}$ & $\begin{array}{l}145 \pm 20 \cdot 3 \\
1 \cdot 00 \pm 0 \cdot 35 \\
1 \cdot 92 \pm 0 \cdot 19 \\
1 \cdot 60 \pm 0 \cdot 45 \\
5 \cdot 88 \pm 7 \cdot 48\end{array}$ & $\begin{array}{l}\text { NS } \\
\text { NS } \\
\text { NS } \\
\text { NS } \\
\text { NS }\end{array}$ \\
\hline
\end{tabular}

All results are expressed as mean $\pm \mathrm{SE}$ of mean.

NS $=$ not significant. 
Pacing time

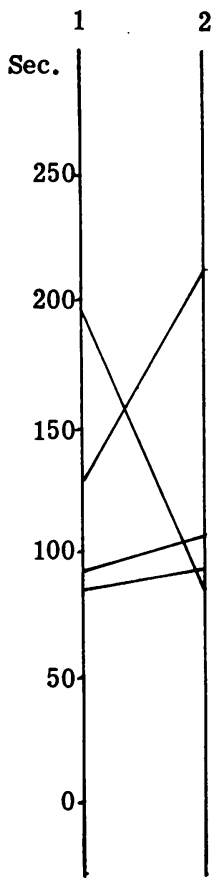

R 1

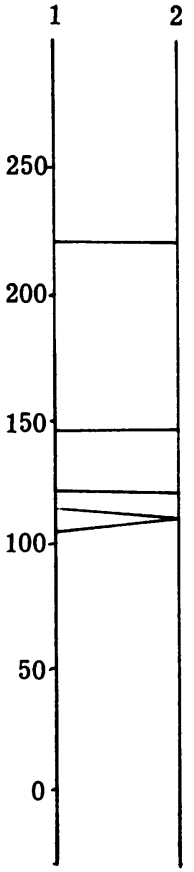

R 2
Lactate extraction

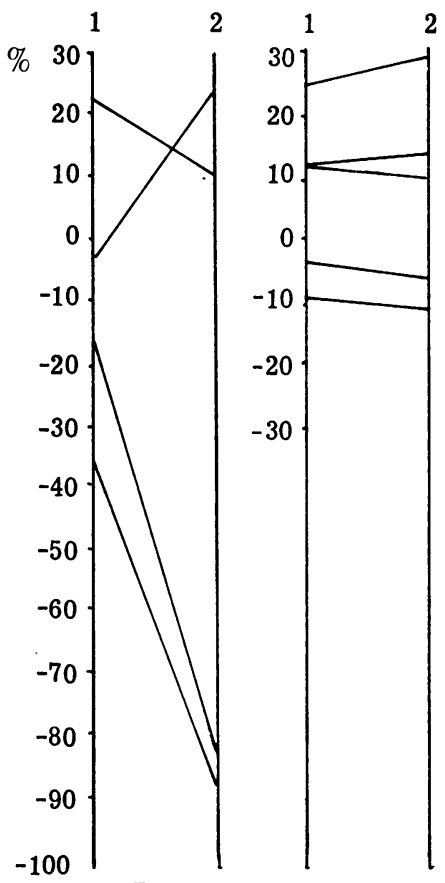

Fig. 1 Effect of atrial pacing on pacing time and on lactate extraction. $R 1$, interval between atrial pacing tests 1 and 2 less than 45 minutes; $R 2$, interval greater than 45 minutes. Measurements of pacing time and lactate extraction are reproducible when the second pacing test follows 45 minutes after the initial pacing test. control pacing test, and 15 minutes later the atrial pacing study was repeated (Fig. 2, Table 2 ). In comparison with the initial control pacing test, intravenous beta-blockade significantly prolonged pacing time to pain $(P<0.01)$, decreased postpacing $S T$ depression $(P<0.05)$ and glucose extraction $(P<0.01)$, and improved myocardial lactate extraction $(P<0.02)$. The prepacing heart rate was significantly lowered. Five patients were converted from lactate production to lactate extraction. Though beta-blockade decreased potassium extraction and increased FFA extraction, these changes were not significant at the 5 per cent level, neither was there any significant difference in myocardial oxygen extraction or prepacing systolic and diastolic arterial pressure between the control patients and those who were treated with a beta-blocker. There were no differences in lactate extraction between control and treated patients 2,5 , and 10 minutes after pacing.

Table 2 Effect of beta-blockade on haemodynamics and myocardial metabolism (11 patients)

\begin{tabular}{|c|c|c|c|c|}
\hline & & Control & Beta-blockade & $P$ \\
\hline \multicolumn{5}{|l|}{ Pacing test } \\
\hline Pacing time (s) & & $212 \cdot 0 \pm 30 \cdot 5$ & $288 \cdot 2 \pm 45 \cdot 9$ & $<0.01$ \\
\hline ST segment depression (mm) & & $1.65 \pm 0.41$ & $1.05 \pm 0.41$ & $<0.05$ \\
\hline Myocardial glucose extraction (\%) & & $12 \cdot 2 \pm 2 \cdot 7$ & $2.9 \pm 2.6$ & $<0.01$ \\
\hline Myocardial lactate extraction (\%) & & $-24 \cdot 6 \pm 19 \cdot 3$ & $1 \cdot 57 \pm 12 \cdot 3$ & $<0.02$ \\
\hline \multirow[t]{2}{*}{ Arteriovenous lactate difference $(\mathrm{mg} / 100 \mathrm{ml})$} & Resting & $1.64 \pm 0.26$ & $1.21 \pm 0.22$ & \\
\hline & Resting minus peak pacing & $3.13 \pm 0.87$ & $1.24 \pm 0.57$ & $<0.002$ \\
\hline Potassium extraction (\%) & & $6.4 \pm 1.2$ & $2 \cdot 6 \pm 2 \cdot 1$ & NS \\
\hline $\begin{array}{l}\text { Myocardial FFA extraction (\%)* } \\
\text { Myocardial } 0 \text {, extraction (\%) }\end{array}$ & & $-2 \cdot 73 \pm 19 \cdot 4$ & $10 \cdot 8 \pm 12 \cdot 6$ & NS \\
\hline \multirow{2}{*}{\multicolumn{5}{|c|}{$\begin{array}{l}\text { Prepacing } \\
\text { Procaral } \mathrm{U}_{2} \text { extraction (\%) }\end{array}$}} \\
\hline $\begin{array}{l}\text { Prepacing } \\
\text { Arterial systolic pressure (mmHg) }\end{array}$ & & & & \\
\hline Arterial diastolic pressure (mmHg) & & $74.6 \pm 3.3$ & $76 \cdot 3 \pm 1 \cdot 2$ & NS \\
\hline Resting heart rate (beats/min) & & $88.2 \pm 3.4$ & $77 \cdot 6 \pm 2 \cdot 7$ & $<0.05$ \\
\hline
\end{tabular}

All results are expressed as mean $\pm S E$ of mean.

*4 patients only. 


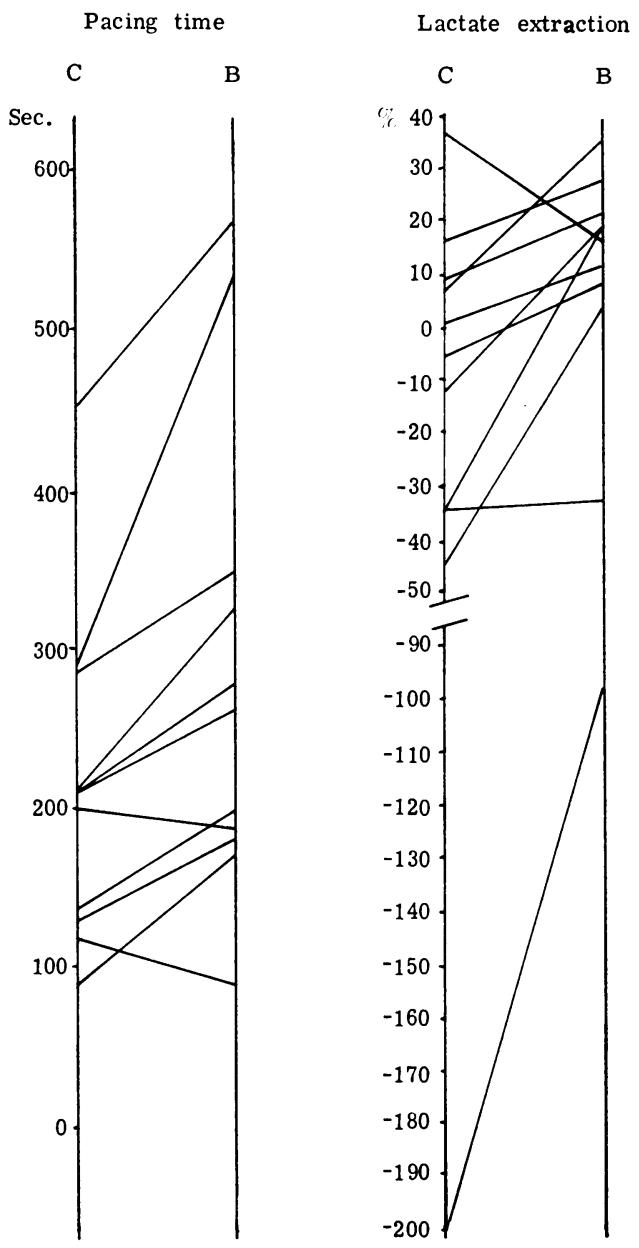

Fig. 2 Atrial pacing stress before and after beta-blockade. Improvement in pacing time and lactate extraction by beta-blockade (B) when compared with control (C).

\section{Discussion}

Myocardial metabolism is normally aerobic, but in the presence of ischaemia anaerobic metabolism develops. This results in a decrease in lactate extraction by the myocardium, with a resultant increase in the lactate content of the coronary sinus. Measurement of myocardial lactate extraction before and after an atrial pacing stress is a reliable means of assessing myocardial ischaemia (Gorlin, 1969). Assessment of the effect of any intervention, for example by drugs or operation, on myocardial lactate metabolism requires that on repeated control tests atrial pacing be associated with a similar time to pain and a similar change in lactate metabolism. Since atrial pacing is terminated by the subjective symptom of chest pain and the time at which this occurs will differ between patients, the degree of change in coronary AV lactate differences during atrial pacing is unique for each individual's pain: he, therefore, must act as his own control. We have shown that if a recovery time of $\mathbf{4 5}$ minutes is allowed, the results of an atrial pacing stress test are reproducible both in time to pain and degree of lactate extraction. Atrial pacing tests repeated before full myocardial recovery will provide misleading information on the therapeutic effectiveness of any particular agent.

After myocardial infarction, beta-blocking drugs have been shown to improve myocardial metabolism at rest (Mueller et al., 1974). However, in patients with angina it was thought that an atrial pacing stress test, in which the effect of the drug on heart rate is eliminated, might fail to show any beneficial effect of beta-blocker (Balcon, 1971). In the clinical situation, improvement can be correlated with a reduction in the peak exercise heart rate (Jackson et al., 1975), but we wondered whether a beneficial effect on myocardial metabolism, similar to that resulting from glyceryl trinitrate (Chiong et al., 1972), was also present. We have shown that when the heart is paced at the same rate in individual patients before and after administration of beta-blocker, pacing time to angina is increased and myocardial lactate extraction significantly improved by the drug. This improvement occurred with both a cardioselective (tolamolol) and a non-selective (propranolol) beta-blocker. Decreased myocardial lactate extraction on atrial pacing may be influenced by both glucose extraction (Most et al., 1972) and a change in the arterial level of FFA (Kaijser et al., 1972). In this investigation beta-blockade significantly decreased glucose extraction. Myocardial ischaemia in man is associated with augmented glucose extraction (Most et al., 1972), and the decrease observed here may be a further reflection of an improvement in myocardial metabolism. There was no significant change in FFA uptake, which in turn increases the sensitivity of lactate as an expression of myocardial ischaemia (Opie et al., 1973).

While the beta-blockers may be improving myocardial metabolism by a direct effect at cellular level, it is also possible that they are reducing myocardial oxygen consumption at peak pacing by reducing ventricular contractility or by affecting coronary blood flow. In this study the reduction in heart rate by beta-blockers was abolished by atrial pacing and there were no changes in arterial pressure. Coronary flow in patients with and without coronary arterial disease is reduced after propranolol both at rest and after exercise. Coronary 
vascular resistance is increased and, associated with this, myocardial oxygen consumption is decreased (Wolfson and Gorlin, 1969); as the vasoconstrictor effect of beta-blockers is accompanied by a reduction in oxygen consumption there may be a change in distribution of myocardial blood flow from non-ischaemic to ischaemic areas (Pitt and Craven, 1970).

Beta-blockade has been shown to reduce mortality in patients after myocardial infarction (Multicentre International Study, 1975) and this may reflect an antiarrhythmic action rather than an effect on reducing the size of the infarct (Julian, 1975). We have shown that beta-blockers produce a significant improvement in myocardial metabolism during angina produced by atrial pacing, and we suggest that this action is related to the documented beneficial effects of beta-blockade on mortality.

This project was supported by a Pfizer research grant. We are grateful to Professor Charles Gray for help with estimations of blood glucose and potassium, to Roger Burgess and John Faulkner of Pfizer for FFA and tolamolol estimation, and Hamish McAinsh of I.C.I. for propranolol estimations.

\section{References}

Andersen, K., Shephard, R. J., Denolin, H., Varnauskas, E., and Masironi, R. (1971). Fundamentals of Exercise Testing. World Health Organization, Geneva.

Balcon, R. (1971). Assessment of drugs in angina pectoris: 3. Postgraduate Medical fournal, 47, Suppl. Advances in adrenergic beta-receptor therapy. 53-58.

Chiong, M. A., West, R. O., and Parker, J. O. (1972). Influence of nitroglycerin on myocardial metabolism and hemodynamics during angina induced by atrial pacing. Circulation, 45, 1044-1056.

Duncombe, W. G. (1963). The colorimetric micro-determination of long-chain fatty acids. Biochemical fournal, 88, 7-10.

Gorlin, R. (1969). Evaluation of myocardial metabolism in ischemic heart disease. Circulation, 39-40, Suppl. IV, 155-163.

Herman, M. V., Elliott, W. C., and Gorlin, R. (1967). An electrocardiographic, anatomic, and metabolic study of zonal myocardial ischemia in coronary heart disease. Circulation, 35, 834-846.
Jackson, G., Atkinson, L., and Oram, S. (1975). Reassessment of failed beta-blocker treatment in angina pectoris by peak exercise heart rate measurements. British Medical fournal, 3, 616-618.

Julian, D. G. (1975). Towards preventing coronary death from ventricular fibrillation. International Lecture American Heart Association 48th Scientific Sessions (abstract). Circulation 51-52. Suppl. II-1.

Kaijser, L., Carlson, L. A., Eklund, B., Nye, E. R., Rossner, S., and Wahlqvist, M. L. (1972). Substrate uptake by the ischaemic human heart during angina induced by atrial pacing. In Effect of Acute Ischaemia on Myocardial Function. Proceedings of the 7th Pfizer International Symposium, Edinburgh, p. 223. Ed. by M. F. Oliver, D. G. Julian, and K. W. Donald. Churchill Livingstone, Edinburgh and London.

Livesley, B., and Atkinson, L. (1974). Accurate quantitative estimation of lactate in whole blood. Clinical Chemistry. 20, 1478.

Most, A. S., Gorlin, R., and Soeldner, J. S. (1972). Glucose extraction by the human myocardium during pacing stress. Circulation, 45, 92-96.

Mueller, H. S., Ayres, S. M., Religa, A., and Evans, R. G. (1974). Propranolol in the treatment of acute myocardial infarction: effect on myocardial oxygenation and hemodynamics. Circulation, 49, 1078-1087.

Multicentre International Study (1975). Improvement in prognosis of myocardial infarction by long-term betaadrenoreceptor blockade using practolol. British Medical fournal, 3, 735-740.

Opie, L. H., Owen, P., Thomas, M., and Samson, R. (1973). Coronary sinus lactate measurements in assessment of myocardial ischemia. American fournal of Cardiology, 32, 295-305.

Parker, J. O., Chiong, M. A., West, R. O., and Case, R. B. (1969). Sequential alterations in myocardial lactate metabolism, S-T segments and left ventricular function during angina induced by atrial pacing. Circulation, 40, 113-131.

Pitt, B., and Craven, P. (1970). Effect of propranolol on regional myocardial blood flow in acute ischaemia. Cardiovascular Research, 4, 176-179.

Robinson, B. F. (1971). The mode of action of beta-antagonists in angina pectoris. Postgraduate Medical fournal, 47, Suppl. Advances in adrenergic beta-receptor therapy. 4144.

Wolfson, S., and Gorlin, R. (1969). Cardiovascular pharmacology of propranolol in man. Circulation, 40, 501-511.

Zucker, I. R., Rothfeld, E. L., and Bernstein, A. (1965). A new multipurpose cardiac catheter. American fournal of Cardiology, 15, 45-47.

Requests for reprints to Dr. Samuel Oram, Cardiac Department, King's College Hospital, Denmark Hill, London SE5 9RS. 